\title{
INOVAÇÃO E EMPREENDEDORISMO COMO CAMINHOS PARA NOVOS MODELOS DE ENSINO/APRENDIZAGEM
}

\section{INNOVACIÓN Y EMPRENDEDORISMO COMO CAMINOS PARA NUEVOS MODELOS DE ENSEÑANZA / APRENDIZAJE}

\author{
Helen Kelle dos Santos Costa* \\ Leandro Cordeiro Pereira de Lima** \\ Marla Miranda Loiola Dore Carvalho*** \\ Hugo Saba Pereira Cardoso**** \\ Eduardo Manuel de Freitas Jorge $\mathrm{e}^{\star \star \star * *}$
}

\begin{abstract}
RESUMO
Introdução: Os tempos modernos exigem da sociedade uma nova postura, novas atitudes, uma nova forma de pensar e ver o mundo. Faz-se necessário assim que a Educação, fundamento para construção de uma sociedade, mais uma vez se reinvente, inove e se adeque as demandas que o processo do desenvolvimento humano requer. Objetivo: Ressaltar a importância da Inovação e do Empreendedorismo como ferramentas para o desenvolvimento de novos modelos de ensino/aprendizagem para que haja uma educação que atenda as novas demandas sociais. Metodologia: $\mathrm{O}$ artigo foi estruturado a partir de uma Pesquisa Bibliográfica sobre teorias e modelos de ensino/aprendizagem através de uma leitura analítica, capaz de identificar as características para a realização efetiva do empreendedorismo na educação de forma inovadora. Resultados: Os modelos de educação estão em processo constante de evolução, a adoção de boas práticas e novos recursos que possam auxiliar no ensino-aprendizagem como agente motivador do empreendedorismo na educação através da inovação é uma realidade a ser revista pela sociedade como um todo. Conclusões: Espera-se que este estudo seja uma importante ferramenta para mudanças comportamentais e/ou econômicas, com o objetivo de tornar bem-sucedidos os resultados para todas as partes envolvidas na

\footnotetext{
*Mestranda em Propriedade Intelectual e Transferência de Tecnologia para a Inovação. E-mail: helenkelle13@hotmail.com

**Mestrando em Propriedade Intelectual e Transferência de Tecnologia para a Inovação. Email: leandrolima.cordeiro@gmail.com.

*** Mestranda em Tecnologias para Educação na Universidade do Estado da Bahia (UNEB). Email: marladore@gmail.com

****Doutor em Difusão do Conhecimento na Universidade Federal da Bahia (UFBA). E-mail: hugosaba@gmail.com

*****Doutor em Difusão do Conhecimento na Universidade Federal da Bahia (UFBA). E-mail: emjorge1974@gmail.com
} 
Helen Kelle dos Santos Costa, Leandro Cordeiro Pereira de Lima, Marla Miranda Loiola Dore Carvalho, Hugo Saba Pereira Cardoso, Eduardo Manuel de Freitas Jorge Inovação e empreendedorismo como caminhos para novos modelos de ensino/aprendizagem

tentativa de corroborar com o ecossistema do empreendedorismo através da multiplicação contínua e crescente do conhecimento.

Palavras-chave: Educação. Educação Empreendedora. Inovação. Modelos de Ensino.

\section{INTRODUÇÃO}

Educar é conduzir o indivíduo a sua condição de ser pensante e agente ativo na sociedade, quebrando paradigmas e barreiras do próprio conhecimento, numa ascendente que o levará a transformar o meio em que vive e atua.

Desta forma, o conhecimento sempre constituiu um ponto central na existência humana, e sempre desempenhou papel vital em todas as fases do desenvolvimento histórico de qualquer sociedade. (ZELEZA, 2005, apud BERNARDES, 2007).

Ao analizar a história do conhecimento humano, percebe-se a sua evolução e por assim dizer a sua constante inovação, seja no meio de transmissão do conhecimento, seja na sua forma de armazenamento ou de aprendizado.

A inovação surge a partir do momento que se atende às necessidades humanas, sendo a educação uma delas. A inovação na educação é latente e primordial para o desenvolvimento de uma sociedade capaz de construir um conhecimento que gere transformação.

Muitos são os modelos de educação desenvolvidos e adotados ao longo da história, cada um com sua particulariedade, valor, importância e contribuição, com o objetivo de resolver problemas identificados dentro da sala de aula. Com o objetivo de amenizar estes gargalos em sala de aula, surge então a necessidade de uma nova abordagem de ensino-aprendizagem, que ultrapassa os muros da sala de aula e alcança a vida profissional do indivíduo de forma direta e indireta, o modelo de ensino Empreendedor.

Toma-se como ponto de partida os quatro pilares de ensino (aprender a conhecer, aprender a fazer, aprender a viver juntos e aprender a ser), a 
Helen Kelle dos Santos Costa, Leandro Cordeiro Pereira de Lima, Marla Miranda Loiola Dore Carvalho, Hugo Saba Pereira Cardoso, Eduardo Manuel de Freitas Jorge Inovação e empreendedorismo como caminhos para novos modelos de ensino/aprendizagem

UNESCO identifica um quinto, em sua revista PRELAC (2004) explicita, por sua importância, um pilar adicional: aprender a empreender.

Nos últimos anos, profundas mudanças têm ocorrido na esfera organizacional da educação brasileira e, de acordo com Perucchi, (2016, p. 136), "a produção do conhecimento nas sociedades modernas envolve instituições de ensino e pesquisa, empresas e governo". Por conseguinte depara-se com a necessidade de incentivar empreendedores no processo educativo, inovando as metodologias e os produtos, assim como a pesquisa no desenvolvimento de ideias empreendedoras.

Demonstrar os diferentes modelos de educação e a importância da inovação como agente incentivador da mudança comportamental e econômica, a fim de fomentar em instituições de ensino a criatividade e a geração de soluções, incitando a gestão empreendedora na educação, alavancando o conhecimento e a pesquisa necessários na construção do conhecimento.

Desse modo, salienta a questão de compreender que a inovação e o empreendedorismo são ferramentas fundamentais para que se desenvolvam modelos de ensino/aprendizagem que suportem a demanda de indivíduos capacitados para os desafios da atualidade e futuros.

Inovando os pensamentos e consequentemente trabalhando o lado congnitivo de cada um e reafirmando os pensamentos de Hansen (2017) apud Jannuzzi (2016), ao tratar que a inovação faz emergir a compreensão de dados em determinados momentos que estão sendo vivenciados.

Para a discussão proposta, o artigo é organizado em 4 seções. Após a introdução e apresentação dos objetivos e aspectos metodológicos da pesquisa, a seção 2 discorre sobre inovação, processos de inovação e inovação na educação. $\mathrm{Na}$ seção 3, disserta-se de forma sucinta sobre os modelos de ensino aprendizagem, discorrendo sobre modelo Tradicional, Empirismo, Inatismo, Humanista e Construtivista, e por fim o modelo de Ensino Empreendedor. Ao final, são descritas considerações a respeito dos modelos de educação e empreendedorismo, bem como a importância da pesquisa. 
Helen Kelle dos Santos Costa, Leandro Cordeiro Pereira de Lima, Marla Miranda Loiola Dore Carvalho, Hugo Saba Pereira Cardoso, Eduardo Manuel de Freitas Jorge Inovação e empreendedorismo como caminhos para novos modelos de ensino/aprendizagem

\section{$1.1 \quad$ Metodologia}

O artigo foi estruturado a partir de uma Pesquisa Bibliográfica sobre teorias e modelos de ensino/aprendizagem através de uma leitura analítica, identificando as características para a realização efetiva do empreendedorismo na educação de forma inovadora. Serão elaboradas considerações a respeito do empreendedorismo na educação e seu suporte para a inovação.

Foram utilizados os bancos de dados, SciELO e ALI/ SEBRAE, entre os meses de agosto a outubro de 2016, bem como a consulta em livros sobre a temática. Os artigos foram selecionados mediante limites de busca que incluíram: Categoria de artigo, artigos publicados em português e inglês, artigos disponíveis na íntegra a respeito do tema, abstracts de artigos internacionais e nacionais sem possibilidade de acesso ao texto na sua totalidade. Todo e qualquer material repetido foi excluído, bem como aqueles que não se enquadraram no formato da busca.

Desta forma a pesquisa classifica-se quanto ao seu objetivo como descritiva, que de acordo com Gil (1996), tem como objetivo descrever características de determinada população, fenômeno ou experiência, e o tipo de abordagem é qualitativa, pois o objetivo da pesquisa não é levantar dados estatísticos e sim buscar compreender a demanda e o uso da informação disponibilizada entre os setores analisados.

\section{INOVAÇÃO}

São evidenciados por Bernardes (2007), vários modelos de inovação: inovação radical, a criação de novas formas de serviços, mesmo que permanecendo as características primárias do próprio; inovação para melhoria, traz o aumento da qualidade de determinadas características sem modificações na estrutura, melhorando competências ou determinadas características técnicas, que conforme Tushman e Henderson (1986 apud BERNARDES, 2007), apoiam nos efeitos de aprendizado que normalmente acompanham qualquer atividade; inovação incremental, que mantém a estrutura geral do 
Helen Kelle dos Santos Costa, Leandro Cordeiro Pereira de Lima, Marla Miranda Loiola Dore Carvalho, Hugo Saba Pereira Cardoso, Eduardo Manuel de Freitas Jorge Inovação e empreendedorismo como caminhos para novos modelos de ensino/aprendizagem

sistema, modificado apenas marginalmente; inovação ad doc, frequente em atividades intensivas em conhecimentos, esta inovação permanece com as características de serviço em resposta a um problema, assegurando uma habilidade de reprodução parcial e indireta; inovação pela recombinação, baseia-se nos princípios elementares de dissociação e de associação das características finais e técnicas, inovação pela formalização ou pela objetivação, traduz a formatação e a padronização das características, permitindo atribuir certo grau de materialidade, que podem ser mecanismos tangíveis, ou inovações de processos e mecanismos intangíveis, a introdução de métodos, de roteiros que descrevem a distribuição de funções, que estruturam os pensamentos e os comportamentos, por exemplo, as matrizes BCG, Matriz Boston Consulting Group, que conforme Morales, 2016, é também conhecida como Matriz Crescimento-Participação, com vistas a possibilitar um melhor gerenciamento de recursos financeiros.

De acordo com Bernardes (2007), índices de inovação como: o manual de Frascati (1993) é um compêndio de pesquisa-desenvolvimento, o manual de Oslo (1992), é uma coletânea de indicadores de inovação e o manual de Oslo revisado (1997).

Assim, há um consenso comum sobre o aumento da relevância dos serviços no contexto econômico e, particularmente, dos serviços baseados em conhecimento, indutores do crescimento (ZELEZA, 2005 apud BERNARDES, 2007, p. 89).

Ainda conforme o autor, o conhecimento é considerado, em alguns contextos teóricos econômicos mais recentes, um "fator de produção", desde que imprescindível na realização do processo produtivo, para a determinação do grau de produtividade do trabalho e do capital, e, como tal, permite não apenas na realização do produto, mas também nas esferas da decisão e de quanto produzir e na circulação de e serviços da economia.

Desta forma é descrito o processo de inovação, as etapas que fazem parte da gestão da inovação e como possui relação com o processo de aprendizagem. 
Helen Kelle dos Santos Costa, Leandro Cordeiro Pereira de Lima, Marla Miranda Loiola Dore Carvalho, Hugo Saba Pereira Cardoso, Eduardo Manuel de Freitas Jorge Inovação e empreendedorismo como caminhos para novos modelos de ensino/aprendizagem

\subsection{Processo de Inovação}

A inovação não ocorre por acaso, mas é fruto de um esforço organizado com esse propósito (SEBRAE, 2015). É o resultado de um trabalho sistemático, criativo e disciplinar.

A adoção de uma sistemática estruturada como o Processo de Gestão da Inovação recomendado pelo SEBRAE pode ser observado na Figura 1 a seguir:

Figura 1. Processo de Gestão da Inovação

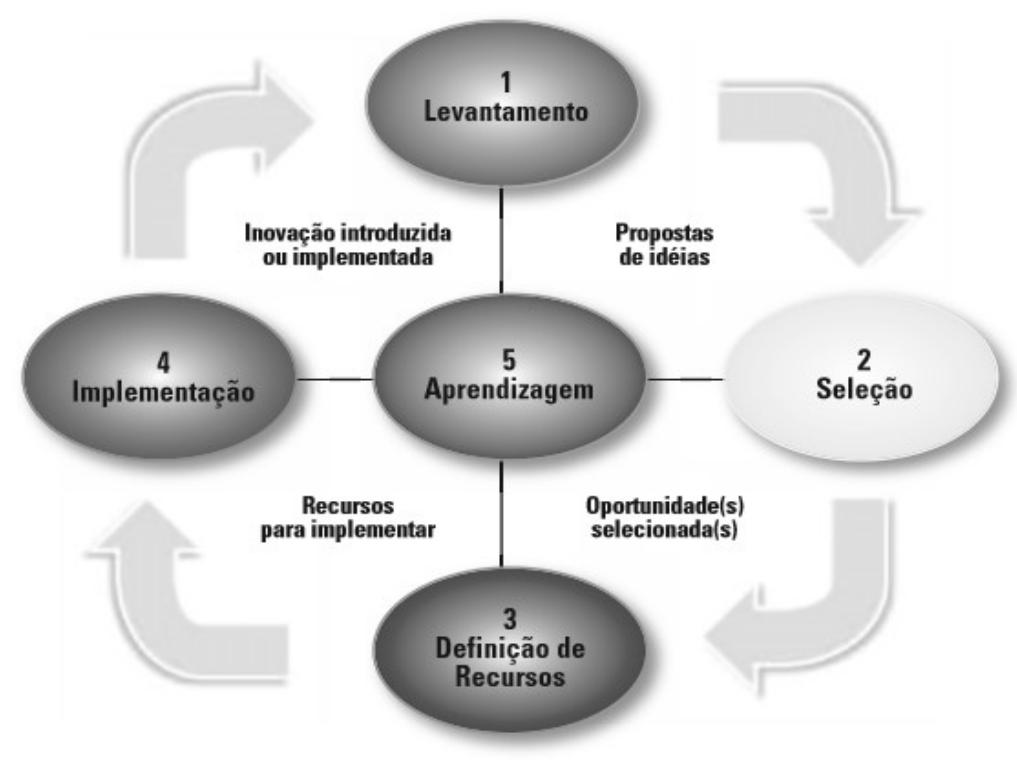

Fonte: Guia de Inovação, SEBRAE (2015)

O Processo de Gestão da Inovação apresentado na Figura 1 permite desenvolver sistemas para inovar de forma continuada, pode ajudar a definir com mais clareza quais são as ideias que podem ser implantadas para desenvolver atividades inovadoras. Realizar reuniões com a equipe (brainstorming) para levantamento e seleção de ideias, definindo quais recursos serão necessários para implementação, que requer aprendizagem contínua em todas as etapas. 
Helen Kelle dos Santos Costa, Leandro Cordeiro Pereira de Lima, Marla Miranda Loiola Dore Carvalho, Hugo Saba Pereira Cardoso, Eduardo Manuel de Freitas Jorge Inovação e empreendedorismo como caminhos para novos modelos de ensino/aprendizagem

As empresas buscam inovar com o objetivo de se manterem e se recolocarem no mercado, de forma a continuar gerando renda e atender as demandas do mesmo. Sejam em processos internos, perpassando todos os seus setores e atividades, marketing, financeiro, gestão, recursos humanos, produção, atendimento, vendas, pós-vendas, entre outros.

Tom Peters (1942), dizia que as empresas excelentes não acreditam em excelência - só em constante melhora e constante mudança. Cabe aos empreendedores a disposição para inovar, ofertando a sociedade uma solução eficaz e capaz de gerar renda para as organizações.

Por conseguinte são descritos alguns dos materiais e métodos aplicados na inovação na educação com base em atividades curriculares e ferramentas utilizadas também em outros países.

\subsection{Inovação na Educação}

A Organização para a Cooperação e Desenvolvimento Econômico (OCDE), em seu relatório sobre Mensuração da Inovação na Educação em um projeto-piloto com 28 sistemas educacionais (entre países, estados americanos e territórios canadenses) no mundo relata que entre as inovações na área de educação analisadas estão materiais didáticos, recursos educacionais, estilo de ensino, aplicação de conhecimento na vida real, interpretação de dados e textos, disponibilidade de computadores e sistemas de e-learning nas aulas, novas formas de organizar atividades curriculares e uso de tecnologia na comunicação com pais e alunos, entre outros (OCDE, 2011).

Porém, os investimentos em tecnologia e inovação não são unanimidade entre estudiosos de educação, já que nem sempre esses investimentos se traduzem em melhor desempenho ou em benefícios mensuráveis - e muitas vezes incorrem em aumento de gastos. Ainda segundo os especialistas da OCDE, mesmo que não haja uma relação facilmente comprovável entre inovação e melhorias na educação, "em geral, países com maiores níveis de inovação veem aumento em alguns resultados educacionais, incluindo melhor 
Helen Kelle dos Santos Costa, Leandro Cordeiro Pereira de Lima, Marla Miranda Loiola Dore Carvalho, Hugo Saba Pereira Cardoso, Eduardo Manuel de Freitas Jorge Inovação e empreendedorismo como caminhos para novos modelos de ensino/aprendizagem

performance em matemática, resultados de aprendizado mais igualitários e professores mais satisfeitos" (OCDE, 2011, p.1).

Para Kenski (2008 apud SILVA, 2015, p.54): "O conceito de tecnologia engloba a totalidade de coisas que a engenhosidade do cérebro humano consegue criar em todas as épocas, suas formas de uso, suas implicações".

Ainda de acordo Silva (2015), as tecnologias terão qualidade e eficiência se, acima de tudo, forem adequadas e pensadas em conjunto com as atividades desenvolvidas em sala de aula, para poderem ser ferramentas de apoio para o melhor e mais amplo desenvolvimento do conhecimento e estimula ao compartilhamento de informações que façam com que os alunos se tornem atores principais do processo. Destacando-se o desafio tecnológico existente no país, principalmente nas cidades mais afastadas das regiões metropolitanas.

No entanto as oportunidades de aplicar a inovação, empreender com os recursos existentes é um desafio mundial, fazendo com que a adequação aconteça respeitando todas as restrições existentes, inovando também a partir das necessidades, sejam estas devido à idade, a falta de prática ou de recursos.

De acordo com Pierre Levy (2004), as tecnologias estão englobando a todos, havendo a necessidade explícita da compreensão de ferramentas, independente da complexidade das mesmas a fim de que possam ser melhor aplicadas no novo cenário de aprendizagem. No entanto, esta compreensão deve passar por um processo de adequação, atentando às habilidades dos educandos em avaliar as fontes de orientações além da visão crítica sobre as informações disponibilizadas.

O conceito de inovação do conhecimento é visto como um processo de otimização do fluxo de competências dentro de um grupo de agentes econômicos e suas múltiplas redes que operam os ambientes, com o objetivo de tornar bem-sucedidos os resultados para todas as partes envolvidas. Isso requer 0 desenvolvimento de métodos de trabalho e técnicas para 0 conhecimento coletivo que lida com o conhecimento disponível e a ação de 
Helen Kelle dos Santos Costa, Leandro Cordeiro Pereira de Lima, Marla Miranda Loiola Dore Carvalho, Hugo Saba Pereira Cardoso, Eduardo Manuel de Freitas Jorge Inovação e empreendedorismo como caminhos para novos modelos de ensino/aprendizagem

rapidamente compartilhar esse conhecimento. Pela avaliação dessas oportunidades, as organizações podem ampliar sua mudança institucional e o contínuo processo de renovação. Essa é uma das dimensões mais fundamentais do uso sistemático dos recursos intelectuais e da adição à criação de valor (AMIDON, 1997 apud BERNARDES, 2007).

De acordo com Bernardes (2007) a inovação não reside nos processos técnicos, mas nas mudanças que eles possibilitam por meio de toda a gama do espectro dos processos de aprendizado (pela prática, o uso, a interação, a consultoria etc.).

De acordo com Machlup (1962 apud BERNARDES, 2007) a educação, pesquisa e desenvolvimento, meios de comunicação, produção de equipamentos de informação e serviços de informação é considera como serviços específicos produtores de conhecimento. Segundo o autor, a educação é visualizada como a mais relevante indústria do conhecimento, complementada pela pesquisa e desenvolvimento, incluindo a invenção e o sistema de patentes utilizado para a promoção da inovação.

Matsura (2005 apud BERNARDES, 2007) salienta que a pesquisa básica e aplicada e a educação superior são componentes fundamentais para a construção da sociedade do conhecimento, criticamente importantes para a mudança. E, a inovação e a pesquisa referem-se a um aspecto vital do vínculo entre o conhecimento e o desenvolvimento, o que limita substancialmente a sua capacidade de identificar os problemas e formular soluções.

De acordo com o Departamento de Patentes e Comércio dos EUA (USPTO), em Rothwell (2013), a importância do conhecimento científico e a capacidade inovadora do país tem forte relação. Conforme pode ser observado na Tabela 1, a seguir: 
Helen Kelle dos Santos Costa, Leandro Cordeiro Pereira de Lima, Marla Miranda Loiola Dore Carvalho, Hugo Saba Pereira Cardoso, Eduardo Manuel de Freitas Jorge Inovação e empreendedorismo como caminhos para novos modelos de ensino/aprendizagem

Tabela 1: Principais indústrias por parte do nível do conhecimento de STEM nos Estados Unidos, 2011

\begin{tabular}{l|c|c|c|c|c} 
& $\begin{array}{c}\text { High-STEM, } \\
\text { Percentage of Jobs }\end{array}$ & $\begin{array}{c}\text { Super-STEM, } \\
\text { Percentage of Jobs }\end{array}$ & $\begin{array}{c}\text { Share of U.S. } \\
\text { High-STEM Jobs }\end{array}$ & $\begin{array}{c}\text { Share of U.S. } \\
\text { Super-STEM } \\
\text { Jobs }\end{array}$ & $\begin{array}{c}\text { Share of } \\
\text { All Jobs }\end{array}$ \\
\hline Utilities & $44 \%$ & $27 \%$ & $2 \%$ & $3 \%$ & $1 \%$ \\
\hline Professional, scientific, and technical services & 39 & 19 & 13 & 15 & 6 \\
\hline Construction & 38 & 17 & 13 & 14 & 7 \\
\hline Mining, quarrying, and oil and gas extraction & 25 & 15 & 1 & 1 & 0 \\
\hline Manufacturing & 30 & 13 & 16 & 17 & 10 \\
\hline Public administration & 27 & 12 & 7 & 8 & 5 \\
\hline Health care and social assistance & 29 & 10 & 20 & 17 & 13 \\
\hline Other services (except public administration) & 17 & 9 & 5 & 6 & 5 \\
\hline Information & 22 & 7 & 2 & 2 & 2 \\
\hline Management of companies and enterprises & 30 & 7 & 0 & 0 & 0 \\
\hline Transportation and warehousing & 10 & 6 & 2 & 3 & 4 \\
\hline Wholesale trade & 9 & 3 & 1 & 1 & 3 \\
\hline Retail trade & 6 & 3 & 4 & 5 & 12 \\
\hline Educational services & 7 & 3 & 3 & 3 & 9 \\
\hline $\begin{array}{l}\text { Administrative and support and waste manage- } \\
\text { ment and remediation services }\end{array}$ & 9 & 3 & 2 & 2 & 5 \\
\hline Agriculture, forestry, fishing and hunting & 4 & 3 & 0 & 1 & 2 \\
\hline
\end{tabular}

Fonte: Brookings análise de O * NET e 2011 EU Censo American Community Survey fornecido pelo IPUMS, p. 12

Pode ser observado na Tabela 1 que, 39\% dos postos profissionais, científica e técnica e da indústria de telecomunicações qualificam-se como Alto STEM (Ciência, tecnologia, engenharia e matemática), preponderando as atividades inventivas a trabalhadores altamente qualificados. O que demonstra a elevação do nível de conhecimento do staff em uma empresa/indústria faz girar a economia e o nível de inovação em diversas áreas.

Conforme Bernardes (2007), a base para alavancagem das competências centrais que conduzem a competividade e ao desenvolvimento da maior parte das organizações está nas atividades de serviços baseados em conhecimento. Resta às organizações públicas e privadas a concepção de estratégias inovadoras que incorporem esses serviços indutores de desenvolvimento econômico.

A pesquisa é uma inovação constante, trazer a pesquisa, os problemas da realidade, o desenvolvimento de projetos para a educação se torna um desafio constante. Sendo outra barreira a adaptação dos modelos de ensino que são descritos a seguir. 
Helen Kelle dos Santos Costa, Leandro Cordeiro Pereira de Lima, Marla Miranda Loiola Dore Carvalho, Hugo Saba Pereira Cardoso, Eduardo Manuel de Freitas Jorge Inovação e empreendedorismo como caminhos para novos modelos de ensino/aprendizagem

\section{MODELOS DE ENSINO APRENDIZAGEM}

O ser humano é composto por 4 (quatro) dimensões básicas, física, mental/intelectual, emocional e espiritual, que o faz ser quem o é, e o torna em quer que ele deseja ser. Uma não anula a outra, ambas, se complementam, interagem entre si, e às vezes se sobrepõe, gerando na pessoa a sua capacidade de ser, sentir, pensar e agir.

Dessa forma o processo educativo perpassa sobre todas essas dimensões, e se faz necessário dar à devida atenção as mesmas para que o docente, por exemplo, alcance o seu objetivo fim, transmitir o conhecimento apresentado em sala com sucesso, ou seja, absorção do conteúdo por parte do discente.

[...] Quando lidamos com pessoas, devemos sempre ter em mente as quatro dimensões do ser humano. Desta forma será mais fácil compreender o outro, será mais fácil delegar tarefas, pedir favores, dialogar, enfim, será um relacionamento mais proveitoso e com melhores resultados. Seja qual for o relacionamento: social, familiar ou profissional. (CASELANE, 2016, p.1).

O ativismo das práticas pedagógicas leva os docentes a não estabelecerem e definirem padrões que por sua vez esgotam em si mesmas, chegando ao ponto de justificarem os meios em função do fim, passa a ter dificuldades para planejar e avaliar, se banaliza o fazer pedagógico, gera insegurança perdendo assim a fundamentação das suas ações. Segundo Freire (1996, p.32) "a educação, qualquer que seja ela, é sempre uma teoria do conhecimento posta em prática", assim, toda atividade desenvolvida por um educador, pressupõe o embasamento em um modelo de ensino aprendizagem, que regimenta tais práticas.

Os modelos de ensino, conhecidos também como teorias ou abordagens, têm por objetivo sanar os problemas educacionais apresentados em sala de aula, como por exemplo, a dificuldade de aprendizagem e a falta de interesse por parte dos alunos. Diversos são os modelos de ensino que visam 
Helen Kelle dos Santos Costa, Leandro Cordeiro Pereira de Lima, Marla Miranda Loiola Dore Carvalho, Hugo Saba Pereira Cardoso, Eduardo Manuel de Freitas Jorge Inovação e empreendedorismo como caminhos para novos modelos de ensino/aprendizagem

à otimização do ensino aprendizagem de forma consciente e clara, como por exemplo, os modelos: Tradicional, Empirismo, Inatismo, Humanista e Construtivista.

No modelo Tradicional de acordo com Mizukami (1986), a abordagem tradicional do processo de ensino aprendizagem não se fundamenta em teorias empiricamente validadas, mas sim numa prática educativa e na sua transmisão através dos anos.

No Empirismo segundo Porto (2006, p.17-18) "na concepção empirista, a educação não se dá a partir da transmissão de um conteúdo, mas no exercício dos métodos que levam à produção dos diferentes tipos de conhecimento".

Já na abordagem do Inatismo de acordo com Porto (2006, p.13) "se aprender é apenas rememorar, então a função do professor é conduzir o aluno no processo de trazer à consciência as ideias que jazem escondidas em sua alma".

O modelo Humanista "trata-se da educação centrada na pessoa, já que nessa abordagem o ensino será centrado no aluno [...]" (ABREU et al, 1997, p. 8).

No Construtivismo segundo Leão (1999, p.201) "o mais importante em relação ao papel do professor na utilização do construtivismo é sua capacidade de aceitar que não é mais o centro do ensino e da aprendizagem". Dessa forma entende-se que o construtivismo oferece ao ser humano o desprendimento de regras pré-estabelecidas para aquisição do conhecimento, conforme pode ser observado na Tabela 2 a seguir.

Tabela 2: Principais Modelos de Ensino Aprendizagem

\begin{tabular}{l|c|l|c|c}
\hline MODELO & PROFESSOR & ALUNO & FUNDAMENTAÇÃO & $\begin{array}{c}\text { CANAL DO } \\
\text { CONHECIMENTO }\end{array}$ \\
\hline Tradicional & $\begin{array}{c}\text { Fonte do } \\
\text { Conhecimento }\end{array}$ & Passivo & $\begin{array}{c}\text { A mente humana é um } \\
\text { receptáculo de informações e } \\
\text { conhecimento, desde as mais } \\
\text { simples as mais complexas, } \\
\text { cabendo ao aluno apenas } \\
\text { estocar estas }\end{array}$ & Por transmissão \\
\hline
\end{tabular}

Inf. Inf., Londrina, v. 22, n. 3, p. 211 - 233, set./out. 2017. http:www.uel.br/revistas/informacao/ 
Helen Kelle dos Santos Costa, Leandro Cordeiro Pereira de Lima, Marla Miranda Loiola Dore Carvalho, Hugo Saba Pereira Cardoso, Eduardo Manuel de Freitas Jorge Inovação e empreendedorismo como caminhos para novos modelos de ensino/aprendizagem

\begin{tabular}{|c|c|c|c|c|}
\hline & & & informações/conhecimento. & \\
\hline Empirismo & $\begin{array}{c}\text { Fonte do } \\
\text { Conhecimento }\end{array}$ & Passivo & $\begin{array}{l}\text { Princípio de que todo o } \\
\text { conhecimento adquirido/passado } \\
\text { provém das experiências vividas, } \\
\text { as experiências são a fonte do } \\
\text { conhecimento. }\end{array}$ & $\begin{array}{c}\text { Experiências, do meio } \\
\text { para o indivíduo }\end{array}$ \\
\hline Inatismo & Mediador & Ativo & $\begin{array}{l}\text { O ser humano já nasce quase } \\
\text { pronto, já nasce com todo } \\
\text { conhecimento necessário. }\end{array}$ & Alma/Mente Humana \\
\hline Humanista & Facilitador & Ativo & $\begin{array}{c}\text { Não há normas a serem seguidas, } \\
\text { perpassa pela capacidade do } \\
\text { indivíduo fazer a seu caminho e } \\
\text { neste processo absorver } \\
\text { informações a serem } \\
\text { transformadas em conhecimento. }\end{array}$ & Experiências particulares \\
\hline Construtivista & Facilitador & Ativo & $\begin{array}{l}\text { O desenvolvimento intelectual do } \\
\text { ser humano está diretamente } \\
\text { relacionado com o seu } \\
\text { organismo e o meio ambiente } \\
\text { que vive, ou seja, através da } \\
\text { interação que ocorre por meio de } \\
\text { duas etapas que se completam, } \\
\text { assimilação e acomodação, que } \\
\text { possibilitará o indivíduo a } \\
\text { alcançar o conhecimento e } \\
\text { aprimorar o seu intelecto. }\end{array}$ & $\begin{array}{l}\text { Interação do indivíduo } \\
\text { com o meio físico e } \\
\text { social }\end{array}$ \\
\hline
\end{tabular}

Fonte: Produção dos autores

A Tabela 2 apresenta o comparativo entre os principais modelos de ensino/aprendizagem, bem como a forma de concepção quanto ao professor/aluno, a fundamentação e o canal de conhecimento. Sendo que a maioria dos modelos traz o aluno como ator ativo dentro do modelo de educação. Destaca-se, no entanto, que os modelos são muitas vezes aplicados de forma mista, com a mesclagem de formatos adequados a cada realidade, cultura, materiais disponíveis e aceitação das partes interessadas. 
Helen Kelle dos Santos Costa, Leandro Cordeiro Pereira de Lima, Marla Miranda Loiola Dore Carvalho, Hugo Saba Pereira Cardoso, Eduardo Manuel de Freitas Jorge Inovação e empreendedorismo como caminhos para novos modelos de ensino/aprendizagem

\subsection{Modelo de Ensino Empreendedor}

A educação é organizada em 4 (quatro) pilares do conhecimento, sugerida por Delors (2003, p. 89-90),

Aprender a conhecer, isto é adquirir os instrumentos de compreensão; aprender a fazer, para poder agir sobre o meio envolvente; aprender a viver juntos, a fim de participar e cooperar com os outros em todas as atividades humanas; finalmente aprender a ser, via essencial que integra as três precedentes.

Estes pilares podem ser canais de construção de um conhecimento sólido e eficaz ao longo da vida do indivíduo, onde todos interligam-se, não podendo considerar apenas um pois todos se complementam e geram um aprendizado capaz de atender as demandas do século vigente. É percebida a necessidade de se reinventar. Deixar o lado criativo ser canal presente no desenvolvimento de metodologias para a produção e transmissão do conhecimento.

\footnotetext{
Desde o início dos seus trabalhos que os membros da Comissão compreenderam que seria indispensável, para enfrentar os desafios do próximo século, assinalar novos objetivos à educação e, portanto, mudar a ideia que se tem da sua utilidade. Um anova concepção ampliada de educação devia fazer com que todos pudessem descobrir, reanimar e fortalecer o seu potencial criativo - revelar o tesouro escondido em cada um de nós (DELORS, 2003, p. 90).
}

Dessa forma percebe-se a necessidade de inovar, fazer diferente ou melhorar o já existente. Oferecer uma educação que permita de fato que o docente apresente e conduza o conhecimento ao discente de forma eficaz, produtiva e empreendedora a ponto de o indivíduo ser capaz de desenvolver bem todas as suas dimensões.

Assim a UNESCO em sua revista PRELAC sugeri um $5^{\circ}$ (quinto) pilar do conhecimento, agregando aos demais propostos por Delors, o pilar aprender a empreender. 
Implica contribuir para discernir qual é o sentido da educação num mundo de incerteza e mudança. É preciso agregar, às aptidões que oferece a educação atual, abordagens para o exercício da cidadania e para a construção de uma cultura de paz. Os quatro pilares de aprendizagem do Informe Delors são um guia excelente para interrogar-se sobre os sentidos da educação; aprender a ser, a conhecer, a fazer e a viver juntos. O PRELAC explicita, por sua importância, um pilar adicional: aprender a empreender (PRELAC/UNESCO, 2004, p.9).

O pilar "Amprender a Empreender", tem por objetivo fomentar uma educação empreendedora dentro das instituições de ensino a fim de oferecer aos indivíduos capacidade de ir além do conhecer, mas transformar este conhecimento em prática, em ação que gere possibilidades da construção do novo.

\begin{abstract}
Espera-se que, no novo milênio, a aprendizagem contribua de forma importante à realização do terceiro objetivo, a tradicional meta estabelecida pela dimensão econômica da educação. No entanto, a evolução de nosso mundo em direção à complexidade e à interdependência faz necessário um quadro mais amplo de aprendizagem ao longo da vida: colocar em primeira linha o progresso pessoal e cultural, assim como o desenvolvimento cidadão - duas necessidades mais de desenvolvimento humano que estão muito longe de estarem ocultas dentro de um estreito enfoque econômico (PRELAC/UNESCO, 2004, p. 38).
\end{abstract}

Vale salientar que quando abordado o tema empreendedorismo na educação, não se restringe ao conceito de geração de lucro, mas trata-se de lançar um novo olhar sob o processo educativo, transformar e/ou remodelar os métodos e abordagens de ensino/aprendizagem especialmente nas instituições públicas de ensino, onde a evasão de alunos é significativa, entre outras deficiências, conforme pode ser observado na Figura 2 a seguir. 
Helen Kelle dos Santos Costa, Leandro Cordeiro Pereira de Lima, Marla Miranda Loiola Dore Carvalho, Hugo Saba Pereira Cardoso, Eduardo Manuel de Freitas Jorge Inovação e empreendedorismo como caminhos para novos modelos de ensino/aprendizagem

Figura 2. Processo de Educação Empreendedora

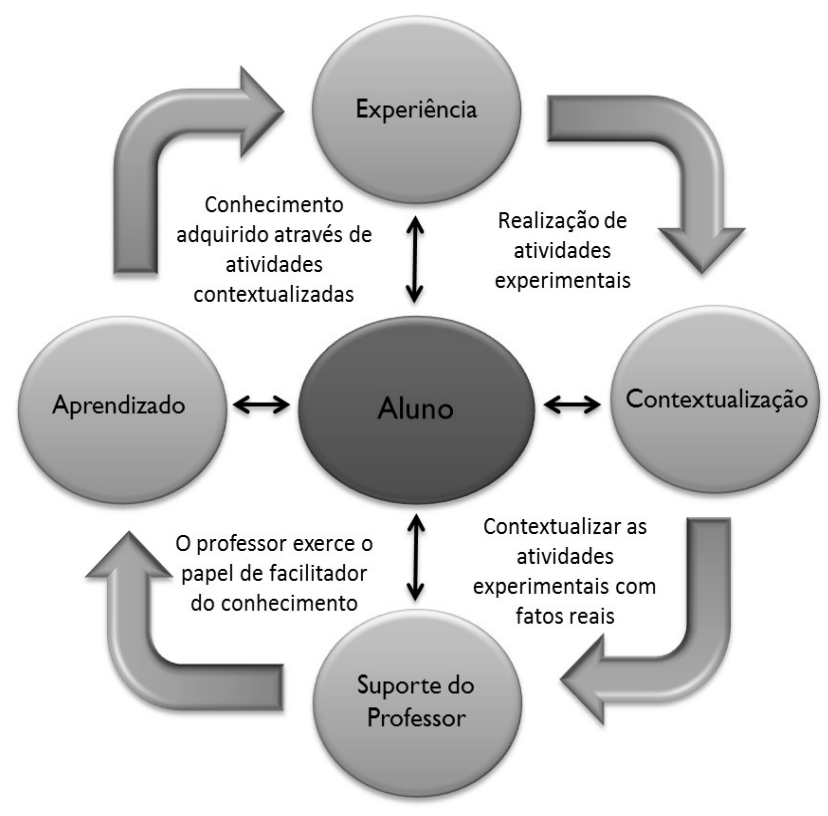

Fonte: Elaborador pelos Autores

O processo ilustrado na Figura 2 apresenta o aluno, a experiência, a contextualização, o suporte do professor e o aprendizado como formas permanentes no processo de ensino/aprendizagem.

O que minimizaria os pontos negativos que de acordo com Liberato (2005, p. 9), “a escola pública é caracterizada pela evasão escolar, apatia, altos índices de repetência, problemas de infraestrutura, falta de professores qualificados (e motivados), estrutura curricular deficiente, falta de recursos e a ausência de políticas públicas efetivas".

Assim, o Modelo de Ensino Empreendedor, já praticado, visa despertar no aluno a sua capacidade de sonhar e realizar estes sonhos, de identificar necessidades e buscar oportunidades e meios de saná-las, de conduzir o indivíduo ao processo de auto-realização, compreendendo assim o pilar principal da educação, aprender a ser, e atingindo todas as suas dimensões humanas. 
Mas Empreendedorismo vai muito mais além do que tudo isso; pressupõe, acima de tudo, a realização do indivíduo por meio de atitudes de inquietação, ousadia e proatividade na sua relação com o mundo. Define-se também, como o tipo de comportamento que favorece a interferência criativa e realizadora no meio, em busca de um crescimento pessoal e coletivo, através do desenvolvimento da capacidade intelectual para investigar e solucionar problemas, tomar decisões, ter iniciativa e orientação inovadora, competências essas, cada vez mais exigidas na formação profissional e valorizadas no mundo do trabalho (LIBERATO, 2005, p.1).

Nesta abordagem de ensino/aprendizagem o aluno é pessoa ativa durante todo o processo de formulação do conhecimento, ele é levado a situações práticas e experimentais a fim de desenvolver nele o comportamento empreendedor.

A educação empreendedora difere-se do modelo de ensino tradicional por se calcar em atividades experienciais, onde 0 aluno é o autor da aprendizagem, e as atividades práticas são contextualizadas com exemplos reais visando preparar o indivíduo para lidar com as incertezas, como falta de recursos e a falta de diferenciação, típicas do início de uma organização. (AZEVEDO et al, 2016, p.4).

Entende-se que a educação empreendedora está direcionada no aprender a aprender, onde o professor exerce o papel de facilitador do conhecimento, para explorar a capacidade do aluno ao máximo e conduzi-lo aos seus objetivos. De acordo com Schaefer et al., (2016, p.65) "outra característica da educação empreendedora é ser uma ação dialógica".

\section{CONSIDERAÇÕES FINAIS}

Diante da demonstração de modelos existentes se faz necessário a adequação de modelos mistos, assim como a constante evolução que traz o aprendiz como ator principal. Os modelos de educação estão em processo constante de evolução, e a adoção de boas práticas e novos recursos que possam auxiliar no ensino-aprendizagem surgem como agente motivador do 
Helen Kelle dos Santos Costa, Leandro Cordeiro Pereira de Lima, Marla Miranda Loiola Dore Carvalho, Hugo Saba Pereira Cardoso, Eduardo Manuel de Freitas Jorge Inovação e empreendedorismo como caminhos para novos modelos de ensino/aprendizagem

empreendedorismo na educação através da inovação é uma realidade a ser revista pela sociedade como um todo.

Como destacado, não foi apontado o melhor modelo, pois a situação, os recursos disponíveis, a cultura, dentre outros fatores irão influenciar diretamente no resultado que a junção de vários ou novos modelos podem gerar um melhor resultado para cada nível escolar envolvido, de forma a compartilhar o conhecimento e principalmente multiplicá-lo.

Levando em consideração todos os desafios locais para aplicação dos modelos, das tecnologias e do processo de aprendizado da utilização das tecnologias pelos professores e alunos, ou mesmo a resistência da cultura na mudança de comportamento e metodologias a serem adotadas.

O agente empreendedor é o elo para levar à inovação para a educação, via metodologia e recursos aplicados a fim de gerar resultados que possam ser aplicados em prol da sociedade como fator importante de destque na incorporação no ambiente de aprendizado.

Países desenvolvidos dão grande importância às formas inovadoras de ensino, e conhecimento. Demonstrando que o maior nível de conhecimento nas empresas impacta em um maior nível de inovação e nos indicadores de crescimento do mercado. Espera-se que este estudo seja uma importante ferramenta para mudanças comportamentais e/ou econômicas. Trazendo a conscientização para a otimização do fluxo de competências dentro de um grupo, com o objetivo de tornar bem-sucedidos os resultados para todas as partes envolvidas que compartilharem esse conhecimento.

O aspecto da importãncia da pesquisa traz a reflexão sobre a existência da extensão dos resultados dos projetos para empresas como agentes motivadores principalmente da economia de um país, fazendo rever a situação atual em que o Brasil se encontra em comparação com a realidade de países desenvolvidos que possuem índices altos de doutores trabalhando no mercado e não somente na área acadêmica. 


\section{REFERÊNCIAS}

ABREU, A. S.; MESQUITA, J. A.; ANCHIETA, J. Abordagens do Processo Ensino-Aprendizagem e o Professor. Brasília, 1997. Disponível em: $<$ http://www.angelfire.com/ak2/jamalves/Abordagem.html>. Acesso em 01 de outubro de 2016.

AZEVEDO, A. C. Manthey, Nilvane Boehm. Lenzi, Fernando César. O ENSINO DO EMPREENDEDORISMO EM CURSOS DE GRADUAÇÃO: PANORAMA DAS PRÁTICAS DOS CURSOS DE CIÊNCIAS SOCIAIS APLICADAS. PasSo Fundo: Encontro de Estudos sobre Empreendedorismo e Gestão de Pequenas Empresas. 16 a 18 de março, 2016.

BARTELL, M. Internationalization of universities: A university culturebased framework. Higher Education. Manitoba: Winnipeg, 2003, p. 37-52.

BERNARDES, R. Inovação em serviços intensivos do conhecimento. São Paulo: Ed. Saraiva, 2007.

Biblioteca SEBRAE, Gestão e Empreendedorismo. Disponível em: $<$ http://www.bibliotecas.sebrae.com.br/chronus/ARQUIVOS CHRONUS/bds/bd s.nsf/5fb9eaac80599677288b70b5485f8f99/\$File/5900.pdf>. Acesso em $01 \mathrm{de}$ outubro de 2016.

Biblioteca SEBRAE, Inovação é a Solução. Disponível em: $<$ http://www.bibliotecas.sebrae.com.br/chronus/ARQUIVOS CHRONUS/bds/bd s.nsf/5fb9eaac80599677288b70b5485f8f99/\$File/5900.pdf>. Acesso em $01 \mathrm{de}$ outubro de 2016;

CASTAÑON, G. A. Construtivismo, Inatismo e Realismo: compatíveis e complementares. Revista Ciências \& Cognição 2007; Vol 10: 115-131. Disponível em: <http://www.cienciasecognicao.org/pdf/v10/m346131.pdf> . Acesso em 01 de outubro de 2016.

COSTA, H. K. S. A importância da fidelização de clientes como diferencial competitivo em empresas do segmento de saúde no município de Guanambi/BA, Artigo ALI - CNPQ/SEBRAE, 2016.

COLELLO, S. M. G. Modelos de ensino: das concepções docentes às práticas pedagógicas. E-Aulas USP. Vídeo Aula: Disciplina Profissão Docente. Disponível em:

<http://eaulas.usp.br/portal/video.action;jsessionid=314A499DD8A3873BB6A39 5CCB53785B2?idltem=631>. Acesso em 01 de outubro de 2016.

DELORS, J. Educação: um tesouro a descobrir. 2ed. São Paulo: Cortez Brasília, DF: MEC/UNESCO, 2003. 
FERREIRA, C. As quatro dimensões do ser humano. Disponível em: $<$ http://www.artigos.com/artigos-academicos/9296-as-quatro-dimensoes-do-serhumano>. Acesso em 02 de novembro de 2016.

FREIRE, P. Pedagogia da Autonomia: Saberes Necessários à Prática educativa. 25a. ed. São Paulo: Paz e Terra, 1996.

GIL, A. C. Como elaborar projetos de pesquisas. 3. ed. São Paulo: Atlas, 1996.

JANNUZZI,C.; FALSARELLA, O.; SUGAHARA, C. Gestão do conhecimento: um estudo de modelos e sua relação com a inovação nas organizações.

Revista Perspectivas em ciência de informação. v. 21, n. 1, 2016.

LEÃO, D. M. M. Paradigmas Contemporâneos de Educação: Escola Tradicional e Escola Construtivista. Cadernos de Pesquisa, n. 107, p. 187-206, julho/1999.

LÉVY, P. As tecnologias da Inteligência: o futuro do pensamento na era da informática. São Paulo: Editora 34, 2004.

LIBERATO, A. C. T. Empreendedorismo na escola pública: despertando competências, promovendo a esperança! Estudo de Caso. Rio de Janeiro: SEBRAE, 2005.

MORALES, S. et all, A Matriz Boston Consulting Group (BCG) no planejamento de marketing em uma universidade privada. Disponível em: $<$ http://www.aedb.br/seget/arquivos/artigos06/912 ARTIGO\%20SEGET.pdf>. Acesso em: 11 set. 2016

MOREIRA, M. A. Aprendizagem Significativa: Um Conceito Subjacente. Brasília: Editora da UnB, 2011. Disponível em: $<$ http://www.if.ufrgs.br/asr/artigos/Artigo ID16/v1 n3 a2011.pdf>. Acesso em: 11 set. 2016

OCBE, CERI-Centre for Educacional Researche and Innovation. Disponível em : <http://www.oecd.org/edu/ceri/brochure CERI-final-all-web\%20Aug\%202013-size.pdf>. Acesso em: 02 out. 2016

PERUCCHI, V; MUELLER, S. Produção de conhecimento científico e tecnológico nos Institutos Federais de Educação, Ciência e Tecnologia: uma investigação sobre a sua natureza e aplicação. Revista Perspectivas em ciência de informação. v. 21. n 1, 2016. Disponível em: $<$ http://portaldeperiodicos.eci.ufmg.br/index.php/pci/article/view/2503/1716>. Acessado em 11 set. 2016 
PORTO, L. S. Filosofia da Educação. Rio de Janeiro: Jorge Zahar, 2006.

PORTAL JOSÉ DORNELAS, O Processo Empreendedor. Disponível em: $<$ http://www.josedornelas.com.br/wpcontent/uploads/2011/11/Empreendedorismo-capitulo-2.pdf>. Acesso em 01 out. 2016.

PORTAL SAIA DO LUGAR, Precisamos falar sobre as oportunidades de empreendedorismo no Brasil. Disponível em:

$<$ http://www.josedornelas.com.br/wpcontent/uploads/2011/11/Empreendedorismo-capitulo-2.pdf>. Acesso em 01 out. 2016.

ROTHWELL, J. The Hidden STEM Economy, 2013. Metropolitan Policy Program at Brookings.

$<$ https://www.brookings.edu/wpcontent/uploads/2016/06/TheHiddenSTEMEcon omy610.pdf>.

RUSSO, M. INOVAÇÃO NO ENSINO DA BIBLIOTECONOMIA NO BRASIL: implantação do bacharelado na modalidade de educação a distância. Revista Informação \& Sociedade: Estudos, v.26, n.1. Disponível em:

http://www.ies.ufpb.br/ojs2/index.php/ies/article/view/28772/15526>. Acesso em: 11 set. 2016

SEBRAE, Guia para a Inovação, 2 Ed. Curitiba: SK Editora, 2015.

SCHAEFER, R. M.; ITALO, F. Educação empreendedora: premissas, objetivos e metodologias. Revista Pensamento Contemporâneo em Administração. Rio de Janeiro, p. 60-81, jul/set 2016.

SILVA, A., MAIA, L. Professores e suas relações com a prática pedagógica em função da região em que atuam. Educação em Revista, Marília, v.16, n.1, p.51-66, jan/jun., 2015

VYGOTSKY L. S, Luria A. R, Leontiev N. A. Linguagem, desenvolvimento e aprendizagem. São Paulo: İ́cone/EDUSP, 1988, 228p.

VYGOTSKY, L. S. A formação social da mente: o desenvolvimento dos processos psicológicos superiores. São Paulo: Martins Fontes, 1998. 7 
Helen Kelle dos Santos Costa, Leandro Cordeiro Pereira de Lima, Marla Miranda

Loiola Dore Carvalho, Hugo Saba Pereira Cardoso, Eduardo Manuel de Freitas Jorge

Inovação e empreendedorismo como caminhos para novos modelos de

ensino/aprendizagem

\title{
Title
}

Innovation and entrepreneurship as pathways for new teaching / learning models

\begin{abstract}
Introduction: Modern times demand from society a new attitude, new attitudes, a new way of thinking and seeing the world. It is thus necessary that Education, the foundation for building a society, once again reinvents, innovates and adapts the demands that the process of human development requires. Objective: To emphasize the importance of Innovation and Entrepreneurship as tools for the development of new models of teaching / learning so that there is an education that meets the new social demands. Methodology: The article was structured from a Bibliographic research on theories and models of teaching / learning through an analytical reading, able to identify the characteristics for the effective realization of entrepreneurship in education in an innovative way. Results: The models of education are in constant process of evolution, the adoption of good practices and new resources that can help in teachinglearning as motivating agent of entrepreneurship in education through innovation is a reality to be reviewed by society as a whole. Conclusions: This study is expected to be an important tool for behavioral and / or economic change, with the aim of making the results successful for all parties involved in the attempt to corroborate with the entrepreneurship ecosystem through continuous and increasing multiplication of knowledge.
\end{abstract}

Keywords: Education. Entrepreneurial Education. Innovation. Teaching Models.

\section{Titulo}

Innovación y emprendedorismo como caminos para nuevos modelos de enseñanza / aprendizaje

\section{RESUMEN}

Introducción: Los tiempos modernos exige de la sociedad una nueva postura, nuevas actitudes, una nueva forma de pensar y ver el mundo. Se hace necesario así que la Educación, fundamento para la construcción de una sociedad, una vez más se reinventa, inove y se adecue las demandas que el proceso del desarrollo humano requiere. Objetivo: Resaltar la importancia de la innovación y el espíritu empresarial como herramientas para el desarrollo de nuevos modelos de enseñanza / aprendizaje para que haya una educación que atienda las nuevas demandas sociales. Metodología: La investigación fue estructurada a partir de una Investigación Bibliográfica sobre teorías y modelos de enseñanza / aprendizaje a través de una lectura analítica, capaz de identificar las características para la realización efectiva del emprendedorismo en la educación de forma innovadora. Resultados: Los modelos de educación están en proceso constante de evolución, la adopción de buenas prácticas y nuevos recursos que puedan auxiliar en la enseñanza-aprendizaje como agente motivador del emprendedorismo en la educación a través de la innovación es una realidad a ser revisada por la sociedad como un "todo. Conclusiones: Se espera que este estudio sea una importante herramienta para cambios conductuales y / o económicos, con el objetivo de hacer exitosos los resultados para todas las partes involucradas en el intento de corroborar con el ecosistema del emprendedorismo a través de la multiplicación continua y creciente del conocimiento . 
Helen Kelle dos Santos Costa, Leandro Cordeiro Pereira de Lima, Marla Miranda Loiola Dore Carvalho, Hugo Saba Pereira Cardoso, Eduardo Manuel de Freitas Jorge Inovação e empreendedorismo como caminhos para novos modelos de ensino/aprendizagem

Palabras clave: Educación. Educación emprendedora. Innovación. Modelos de Enseñanza.

Recebido em: 30.11.2016

Aprovado em: 07.12.2017 